\title{
De portador de conocimiento a mediador de saberes disciplinares: el perfil del profesor de bibliotecología-archivística y ciencia de la información ${ }^{1}$
}

\author{
From Knowledge Carrier to Disciplinary Knowledge Mediator: The profile of the \\ Professor of Library-archival Science and Information Science
}

Orlanda Jaramillo

Escuela Interamericana de Bibliotecología, Universidad de Antioquia

\begin{abstract}
Resumen
El texto presenta un panorama sobre el perfil del profesor de bibliotecologíaarchivística y ciencia de la información, el cual depende tanto de las características del plan de estudios (proyecto pedagógico, modelo educativo) como de las características del profesor. Los resultados se presentan en dos apartados: uno relacionado con la búsqueda documental, en el cual se expone mapas de ideas, agrupados en cuatro áreas (fundamentación teórica, organización y representación de la información y el conocimiento, gerencias y $\mathrm{TIC}$ ); el otro corresponde a las características propias de los profesores adscritos a las universidades colombianas que imparten formación en el área.
\end{abstract}

Palabras Clave: perfil docente/ profesor universitario/ bibliotecología/ archivística/ ciencia de la información.

\section{Abstract}

The text presents an overview of the profile of the teacher of library-archival and information science, which depends both on the characteristics of the curriculum (pedagogical project, educational model) and the characteristics of the teacher. The results are exposed in two sections: one related to the 
documentary search, which are presented in idea maps, grouped into four areas (theoretical foundation, organization and representation of information and knowledge, management and ICT); the other corresponds to the characteristics of the professors attached to the Colombian universities that provide training in the area.

Keywords: teacher profile/ university professor/ library science/ archivology/ information science.

\section{Contexto de la educación superior en Colombia}

La educación superior, entendida como el conjunto de procesos orientados a la formación de sujetos políticos -capaces de transformar la realidad-y a ser fuente de conocimiento desde la investigación teórica y aplicada, tiene por misión ser un motor del desarrollo científico, social, económico y cultural del país y ser uno de los polos de la educación a lo largo de la vida que se fundamenta en cuatro pilares: aprender a conocer, aprender a hacer, aprender a vivir juntos, aprender a ser; pilares enmarcados en los ejes misionales de docencia, investigación y proyección a la sociedad; y de los principios de autonomía institucional y de libertad académica.

Así, la educación superior en Colombia está determinada por directrices, tanto de carácter interno -propias de cada institución de educación superior- como de carácter externo -las dictaminadas por los organismos de dirección, evaluación y control de la educación, como son el Sistema Nacional de Educación Superior y el Consejo Nacional de Acreditación-. Concretamente, la Ley 30 de 1992: Ley de Educación Superior, aboga por la autonomía universitaria y la libertad de cátedra; igualmente el Decreto 2912 de 2001: Régimen de Salarios y Prestaciones establece parámetros para el mejoramiento docente, como es la evaluación periódica de méritos y la constitución del salario con base en un sistema de puntos que fija el salario de acuerdo con la experiencia profesional, el nivel de formación y la 
producción académica. Sin embargo, esta normatividad no define criterios para el perfil del profesor universitario en áreas específicas, es por ello que una situación recurrente en educación superior es la carencia de un perfil docente para cada carrera universitaria.

\section{Competencias del profesor en bibliotecología}

Las competencias del profesor universitario responden a aspectos de carácter disciplinar, laboral y pedagógico que influyen de manera decisiva en los procesos formativos. De ahí que la formación permanente e integral se constituya en una de las acciones principales para la transformación constante de sus saberes, actitudes y aptitudes dentro del ejercicio docente y profesional, al igual que el fortalecimiento de las habilidades en investigación y extensión, para dar cuenta del contexto, de las tendencias emergentes y de las necesidades del medio profesional, esto es la "creación de conocimiento innovador, productivo, donde transmitir lo último sería verdaderamente lo importante y significativo en el rol del profesorado" (Bozu \& Canto, 2009, p.92).

En este orden de ideas, el profesor universitario tiene el compromiso de investigar, transferir e innovar en su contexto, lo que se traduce en tener una actitud constante de reflexión y crítica, de auto-perfeccionamiento y compromiso ético con la profesión; actitud que se refleja con la participación y desarrollo de la investigación en el área de desempeño, en la apuesta por responder a las necesidades de transformación y avance de la disciplina, pues "lejos de oponerse la investigación a la docencia, se potencian mutuamente, por cuanto el saber producido a través de la investigación circula en las aulas que constituyen un primer ámbito de validación" (Rodríguez, 2008, p.57).

El profesor tiene la responsabilidad de formar profesionales para brindar solución a las situaciones de la sociedad; es por ello que el establecimiento del perfil del profesor en el campo de la Ciencia de la Información se debe fundamentar desde las 'Core Competencies' que la Special Library Association (2016) clasifica en ocho áreas: fundamentación teórica, organización de la información y el conocimiento, tecnologías de la información y la 
comunicación, recursos de información y del conocimiento, recuperación y análisis de la información, servicios de información y del conocimiento, ética informacional y competencias complementarias. Estas áreas en Colombia son asumidas por cinco universidades que ofrecen programas de formación profesional, los cuales tienen una duración entre ocho y diez semestres académicos, con diferentes denominaciones y titulaciones, cuyo título más usual es "Profesional en Ciencia de la Información-Bibliotecología" como se ilustra en el Cuadro 1.

Así, el desarrollo de los procesos formativos en bibliotecología-archivística dependen tanto de las características del plan de estudios (proyecto pedagógico, modelo educativo) como de las características del profesor (competencias y calidad). Justamente son estas características las que determinan el perfil docente y su congruencia con el modelo educativo, definido como una herramienta conceptual que representa el proceso de enseñanza aprendizaje, y que recoge los fundamentos axiológicos, pedagógicos y epistemológicos propios de un programa académico o de una IES que permite diferenciar la institución de otras instituciones, o el mismo programa académico impartido en otra IES.

\section{Cuadro 1}

IES que ofrecen programas de formación profesional en el área

\begin{tabular}{ll}
\multicolumn{1}{c}{ Institución } & \multicolumn{1}{c}{ Títulos que otorga } \\
\hline $\begin{array}{l}\text { Corporación Universidad de la Costa } \\
\text { CUC (Institución privada) }\end{array}$ & $\begin{array}{l}\text { Profesional en Ciencia de la Información - } \\
\text { Bibliotecología }\end{array}$ \\
\hline $\begin{array}{l}\text { Fundación Universitaria para el } \\
\text { Desarrollo Humano -Uninpahu } \\
\text { (Institución privada) }\end{array}$ & $\begin{array}{l}\text { Profesional en Ciencia de la Información: } \\
\text { Bibliotecología, Documentación y y }\end{array}$ \\
\hline $\begin{array}{l}\text { Pontificia Universidad Javeriana } \\
\text { (Institución privada) }\end{array}$ & Archivística \\
\hline $\begin{array}{l}\text { Universidad de Antioquia (Institución } \\
\text { pública) }\end{array}$ & $\begin{array}{l}\text { Profesional en Ciencia de la Información- } \\
\text { Universidad de La Salle (Institución } \\
\text { privada) }\end{array}$ \\
\hline $\begin{array}{l}\text { Universidad del Quindío (Institución } \\
\text { pública) }\end{array}$ & Archivística \\
\hline
\end{tabular}

Fuente: Elaboración propia. Diseño de la investigación. 


\section{Método}

La investigación se desarrolló desde un enfoque mixto que combinó el método la investigación documental con la aplicación de una encuesta a los profesores adscritos a los programas. Para la búsqueda documental se definieron tres tipos de fuentes: bases de datos interdisciplinares (DialNet, DOAJ, EBSCO, Emeral@, Science Direct y Web of Science), repositorios especializados (E-lis, Redalyc y Scielo), repositorios pertenecientes a cuatro universidades colombianas que ofrecen el programa de Bibliotecología (Universidad de Antioquia, Pontificia Universidad Javeriana, Universidad de La Salle y Universidad del Quindío) y el metabuscador Carrot2.

Además de las fuentes documentales, se buscó información en las bases de datos de las IES, la Plataforma ScienTI-Colciencias (CVLAC), el Directorio de expertos en el tratamiento de la información (EXIT), el sitio web de los programas de formación profesional en el área y el Sistema Nacional de Información de la Educación Superior-SNIES (Colombia). Los documentos recuperados fueron sometidos al software Voyant.

Para la recolección de la información, relacionada con los profesores adscritos a los programas de formación en bibliotecología-archivística, se aplicó la técnica de la encuesta, acompañada de los instrumentos como guía de encuesta y ficha analítica. El cuestionario fue diseñado bajo los lineamientos discutidos y consensuados por los participantes del Seminario de Educación Bibliotecológica (2015); comprendió 28 preguntas (de carácter cerrado, abierto, selección múltiple y completación) y seis áreas (datos personales, formación disciplinar, desempeño docente, desempeño en investigación, desempeño laboral y desempeño en proyección universitaria). La tasa de retorno fue del $57 \%$. Sumado a ello se tuvo en cuenta aspectos del contexto colombiano, determinados por la Ley 30 de Educación Superior. 


\section{Resultados}

Los resultados se presentan en dos apartados, uno relacionado con la búsqueda documental (Iberoamérica, en el periodo 2005-2015) y otro de los datos de la encuesta: características del profesor adscrito a los programas de bibliotecología-archivística.

En relación con la búsqueda documental, inicialmente se delimitó la búsqueda geográficamente en Colombia obteniendo resultados insignificantes, situación que conllevó a ampliar el criterio geográfico a Iberoamérica. Esta ampliación permitió conocer trabajos de autores colombianos que han investigado sobre el tema desde el ámbito de América Latina y que han sido publicados en otros países de la región. Una característica de la mayoría de los estudios encontrados es que son resultados de las investigaciones realizadas en el marco del Seminario de Educación Bibliotecológica, coordinado por el Instituto de Investigaciones en Bibliotecología e Información-IIBI de la Universidad Autónoma de México-UNAM. A continuación se exponen, en mapas de ideas, los estudios seleccionados.

\section{a) Área de fundamentación teórica}

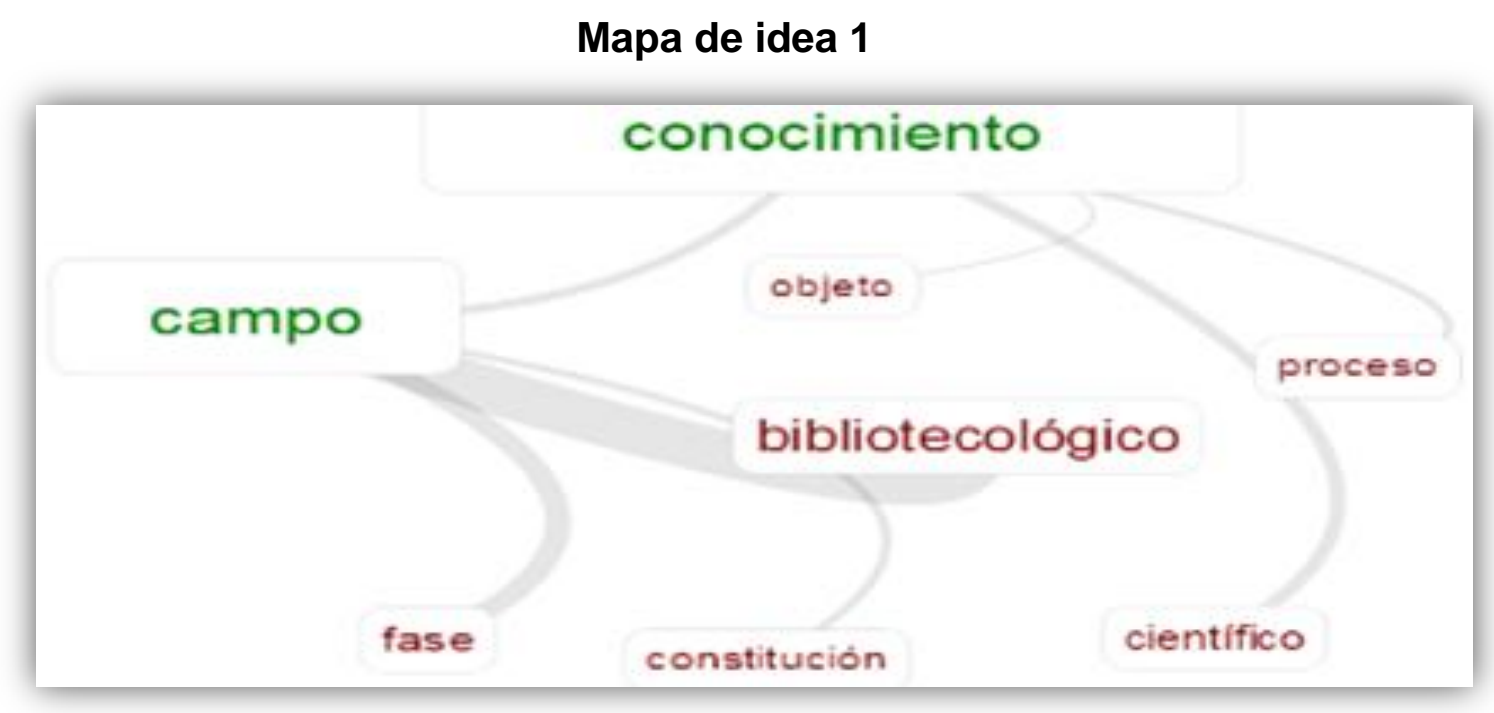

Fuente: Alfaro, H. (2010). Estudios epistemológicos de Bibliotecología. México: UNAM. 


\section{Mapa de idea 2}

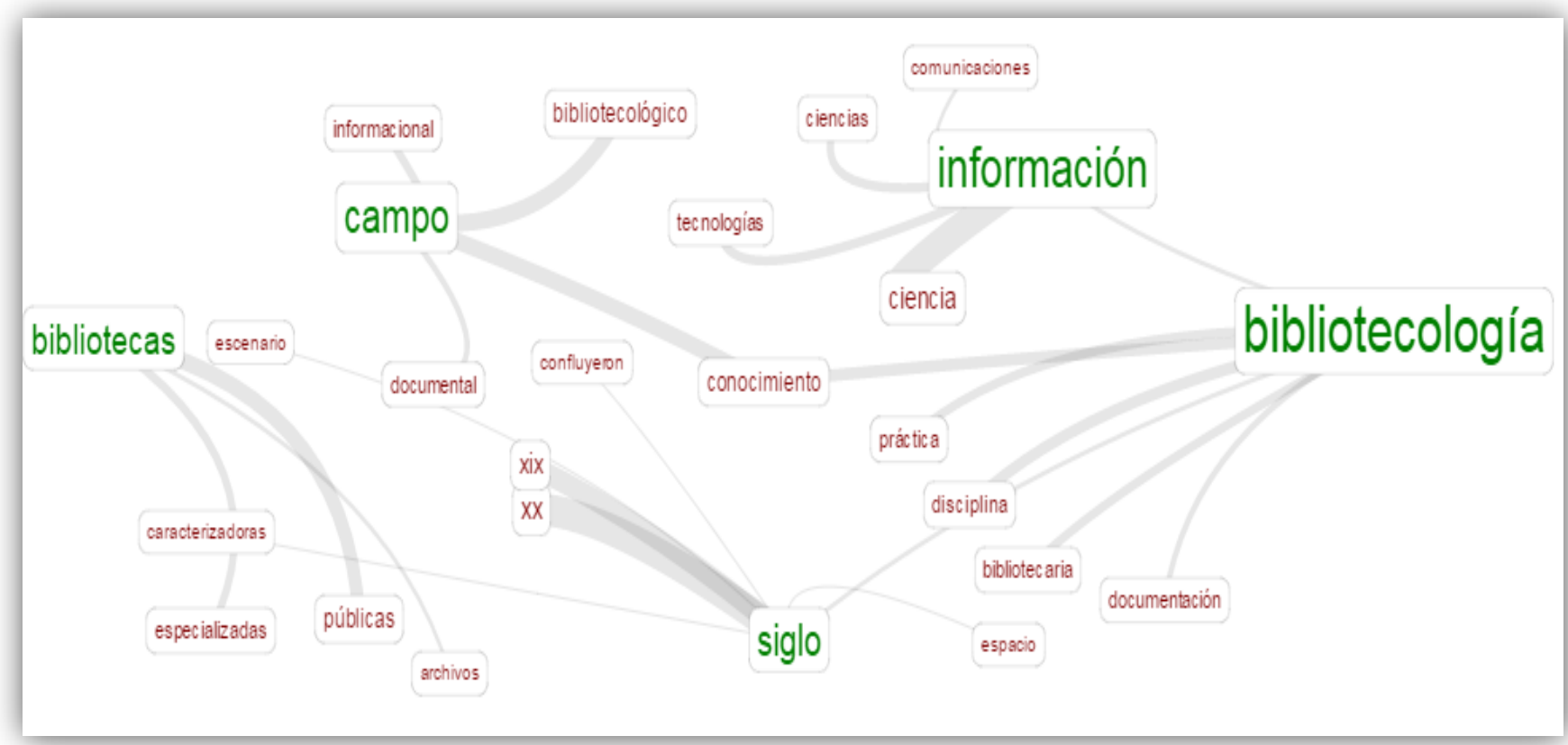

Fuente: Linares, R. (2015). La Bibliotecología en dos tiempos. Revista Cubana de Información en Ciencias de la Salud, 26 (4).

\section{Mapa de idea 3}

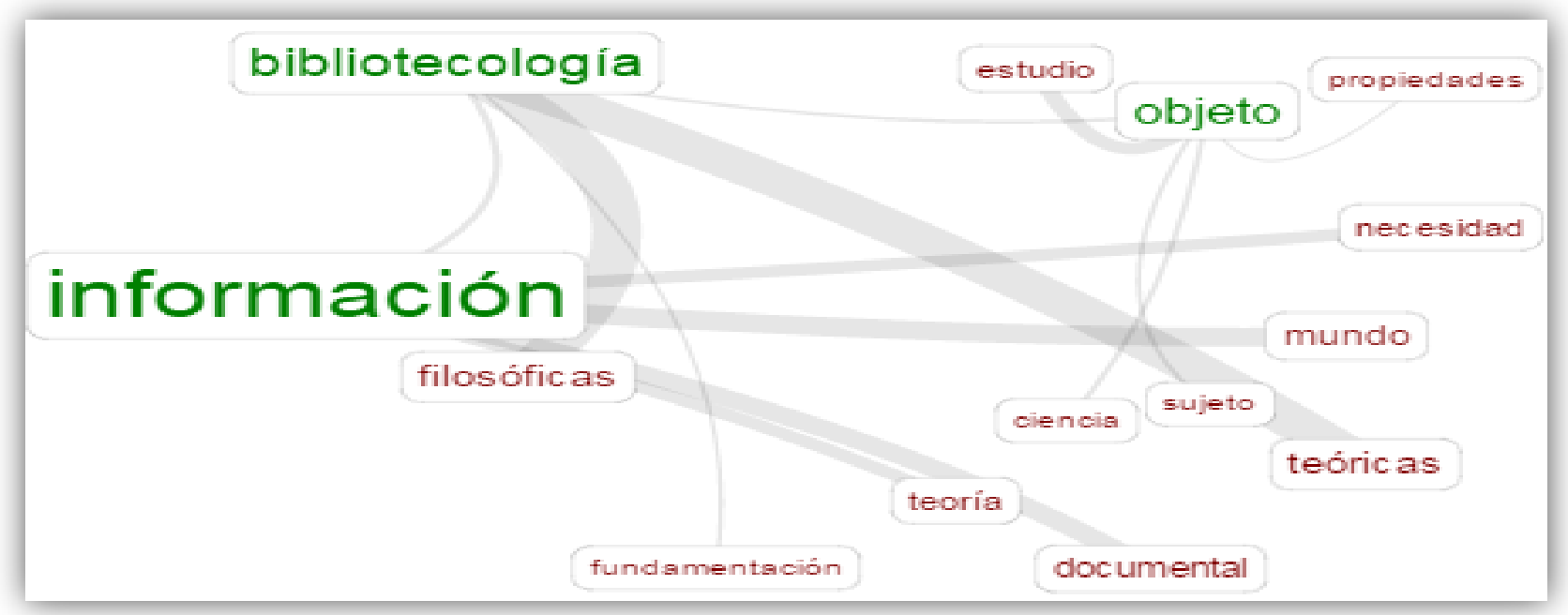

Fuente: Rendón, M. (2008). Ciencia bibliotecológica y de la información en el contexto de las ciencias sociales y humanas. Epistemología, metodología e interdisciplina. Investigación bibliotecológica, 22(44). 


\section{Mapa de idea 4}

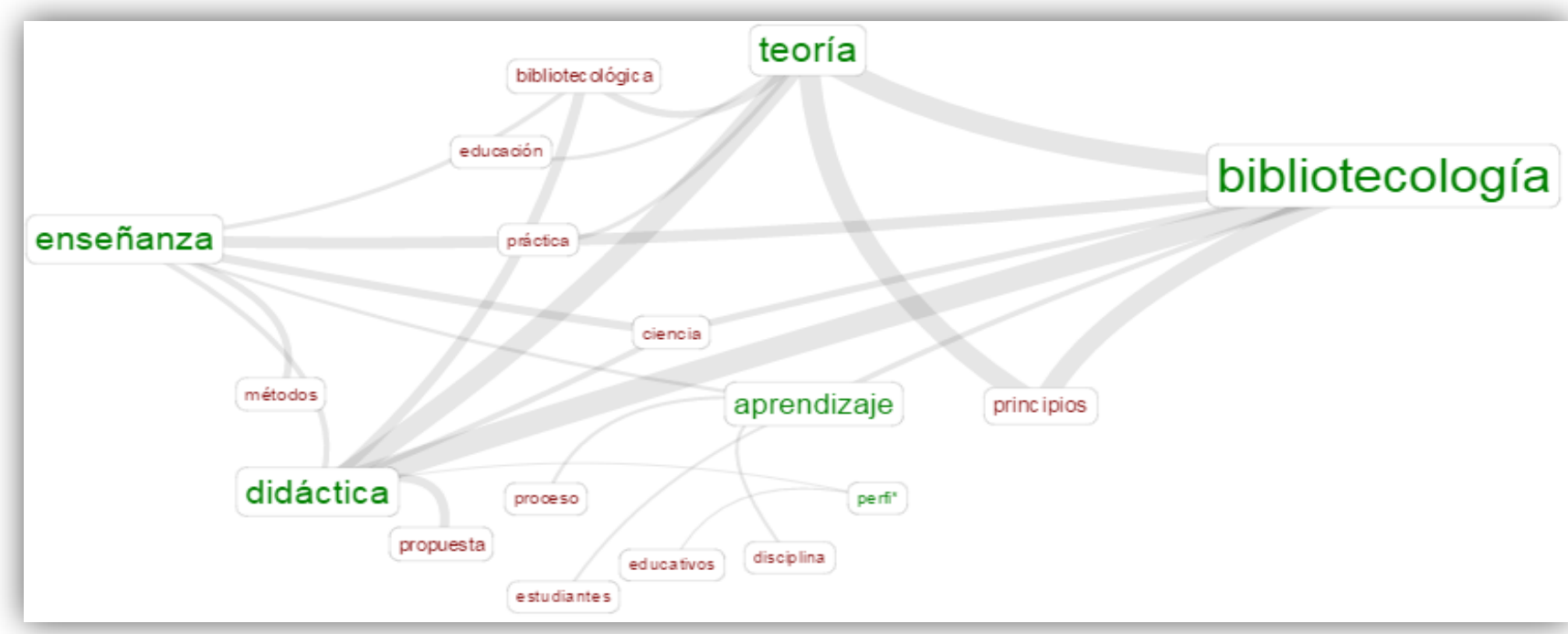

Fuente: Ríos Ortega, Jaime. (2007). La teoría en la educación bibliotecológica: directrices básicas para su enseñanza. Investigación bibliotecológica, 21 (42).

\section{Mapa de idea 5}

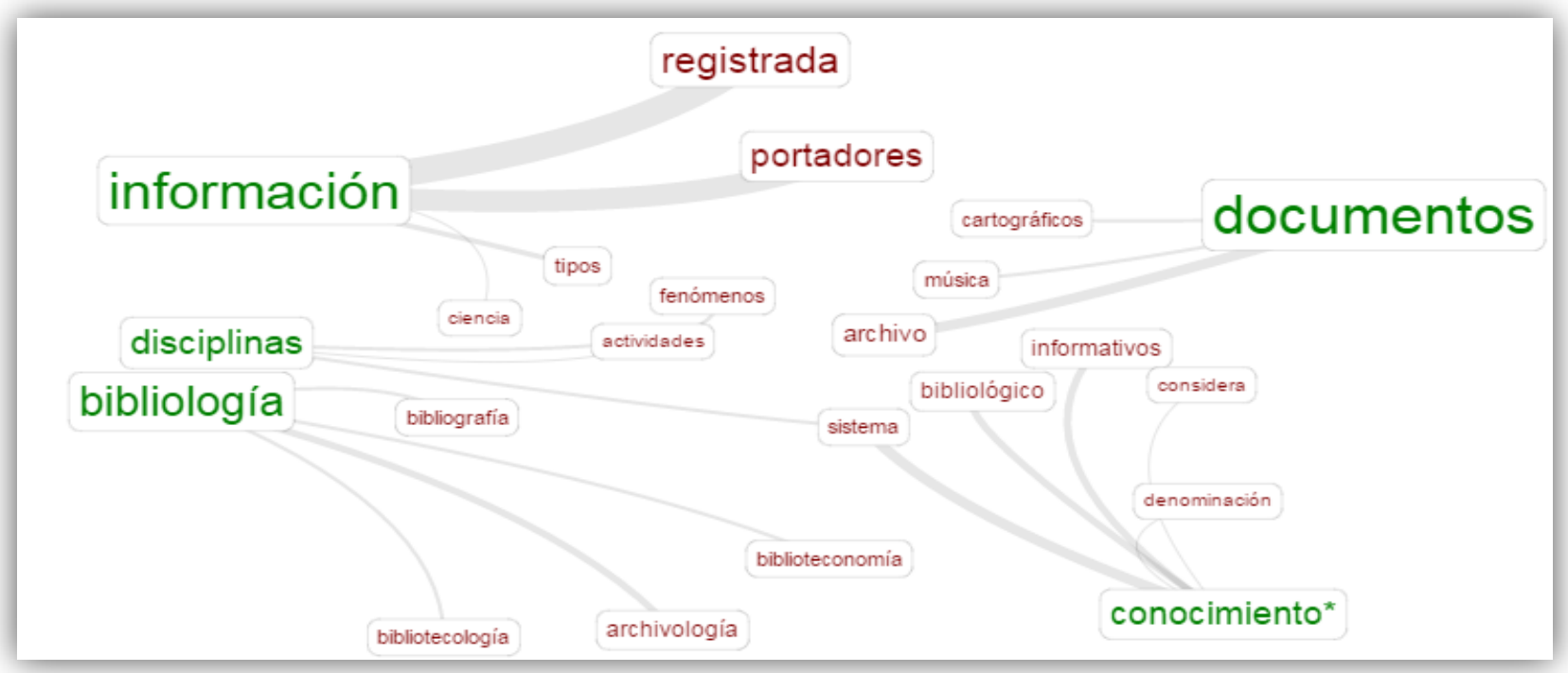

Fuente: Setién-Quesada, Emilio. (2007). Consideraciones sobre la bibliología desde la perspectiva de la teoría bibliológico-informativa. ACIMED, 15 (2).

En esta área se destacan a Setién Quesada, Rendón Rojas, Alfaro López, Ríos Ortega y Linares Columbié quienes se centran en la definición de enfoques epistémicos, directrices 
para la enseñanza y buenas prácticas del quehacer bibliotecológico, enunciándolas como competencias cuya potenciación es posible, solo mediante la investigación.

b) Área de organización y representación de la información y el conocimiento

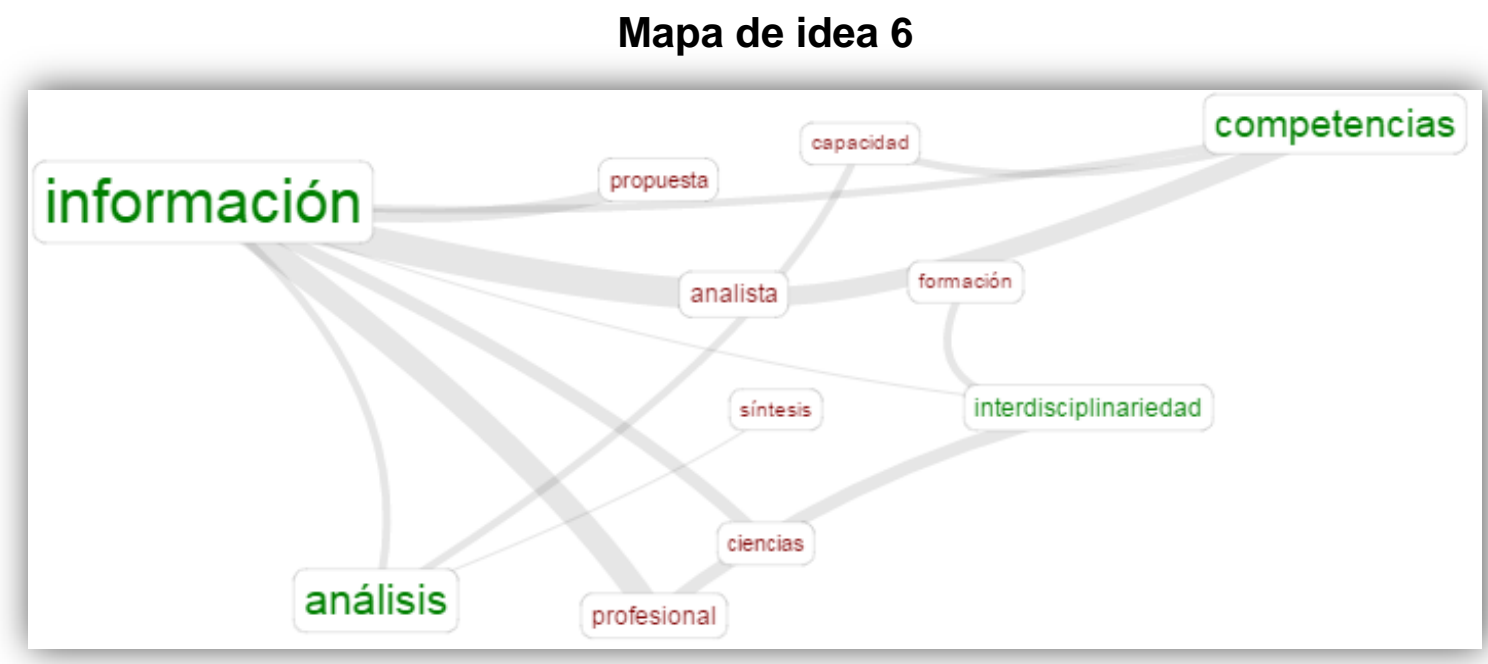

Fuente: Castro, Y., y Chávez, Y. (2012). La interdisciplinariedad en la formación profesional del analista de información: propuesta de competencias. Ciencias de la Información, 43 (2).

Mapa de idea 7

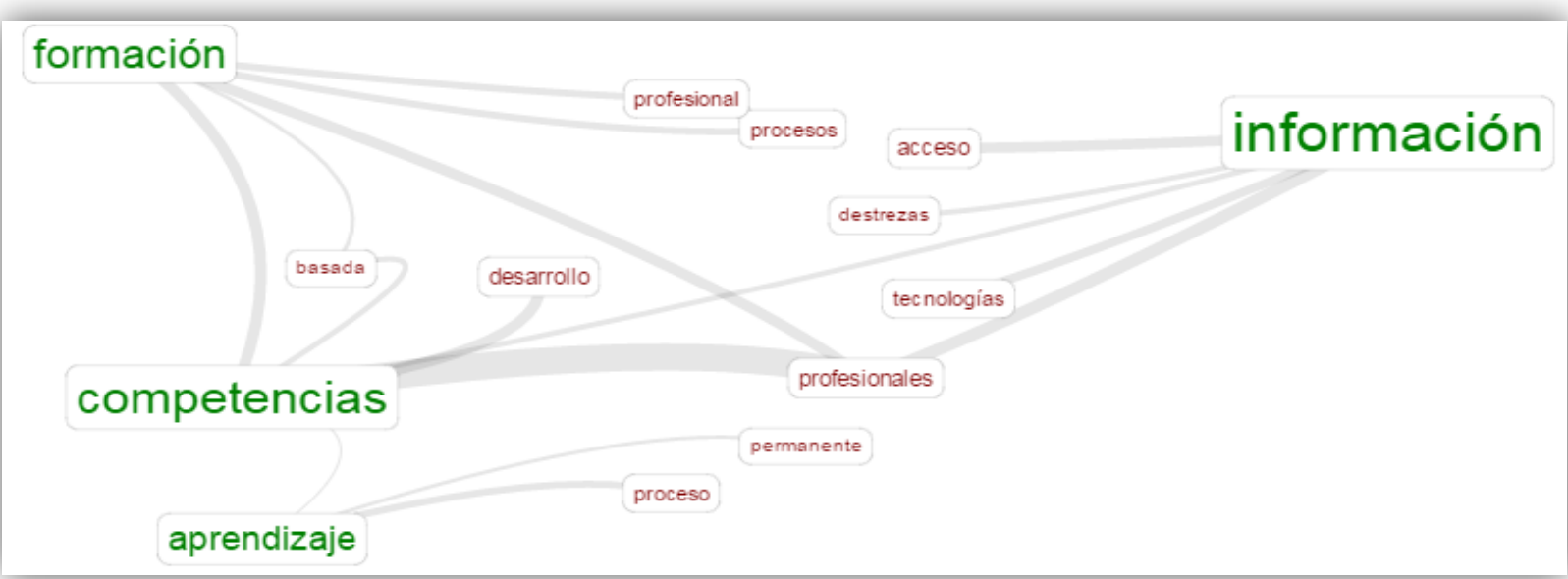

Fuente: Durrieu, M. y otros (2011). Competencias profesionales: una mirada desde la formación en los procesos técnicos. VII Encuentro Internacional y III Nacional de Catalogadores Argentina. 


\section{Mapa de idea 8}

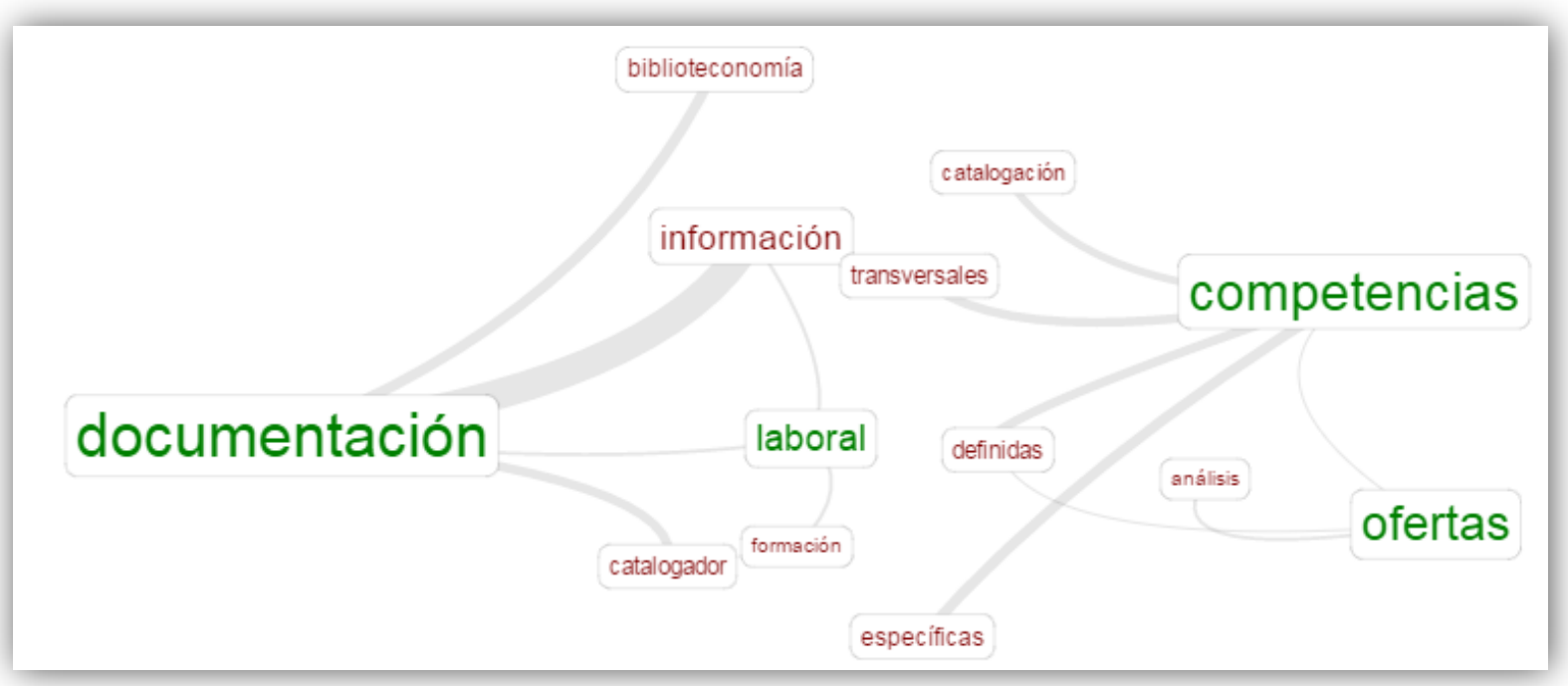

Fuente: Ríos, A., y Sánchez, M. (2011). El perfil actual del personal catalogador: adecuación entre la formación universitaria y la demanda laboral. Anales de Documentación, 14 (2), 1-17.

\section{Mapa de idea 9}

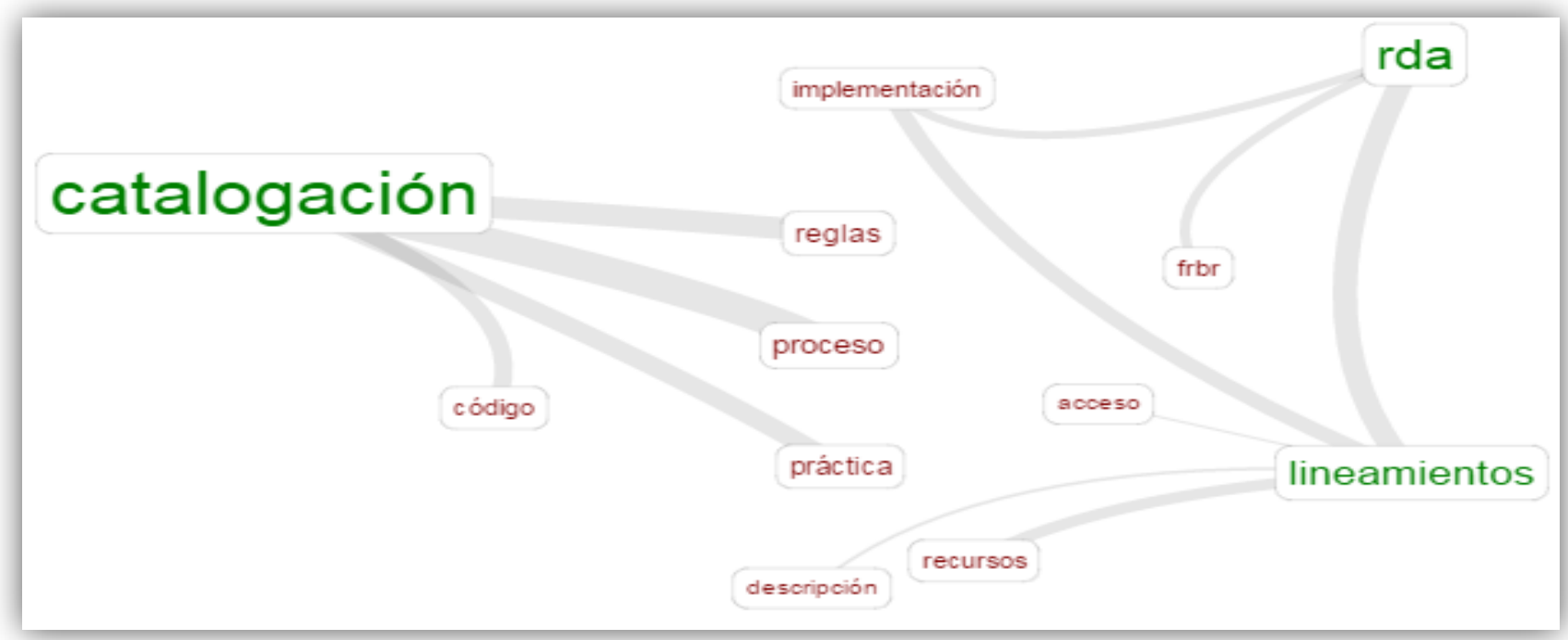

Fuente: Rodríguez, A. (2012). Claves para la implementación de los lineamientos recursos, descripción y acceso. Investigación Bibliotecológica: Archivonomía, Bibliotecología e Información, 26 (56). DOI: http://dx.doi.org/10.22201/iibi.0187358xp.2012.56.33177. 
Los estudios analizados en el área de organización y representación de la información y el conocimiento abordan las competencias en la aplicación de métodos, técnicas e instrumentos a partir de nuevos estándares de catalogación como el RDA. Entre los autores más representativos se encuentran Durrieu y otros, Ríos Hilario y Sánchez García, Castro Viguera y Chávez Montejo y Rodríguez García, quienes transversalizan las TIC como herramientas necesarias para la realización de los procesos y procedimientos para la recuperación, organización y difusión de la información.

c) Área de gerencia

Mapa de idea 10

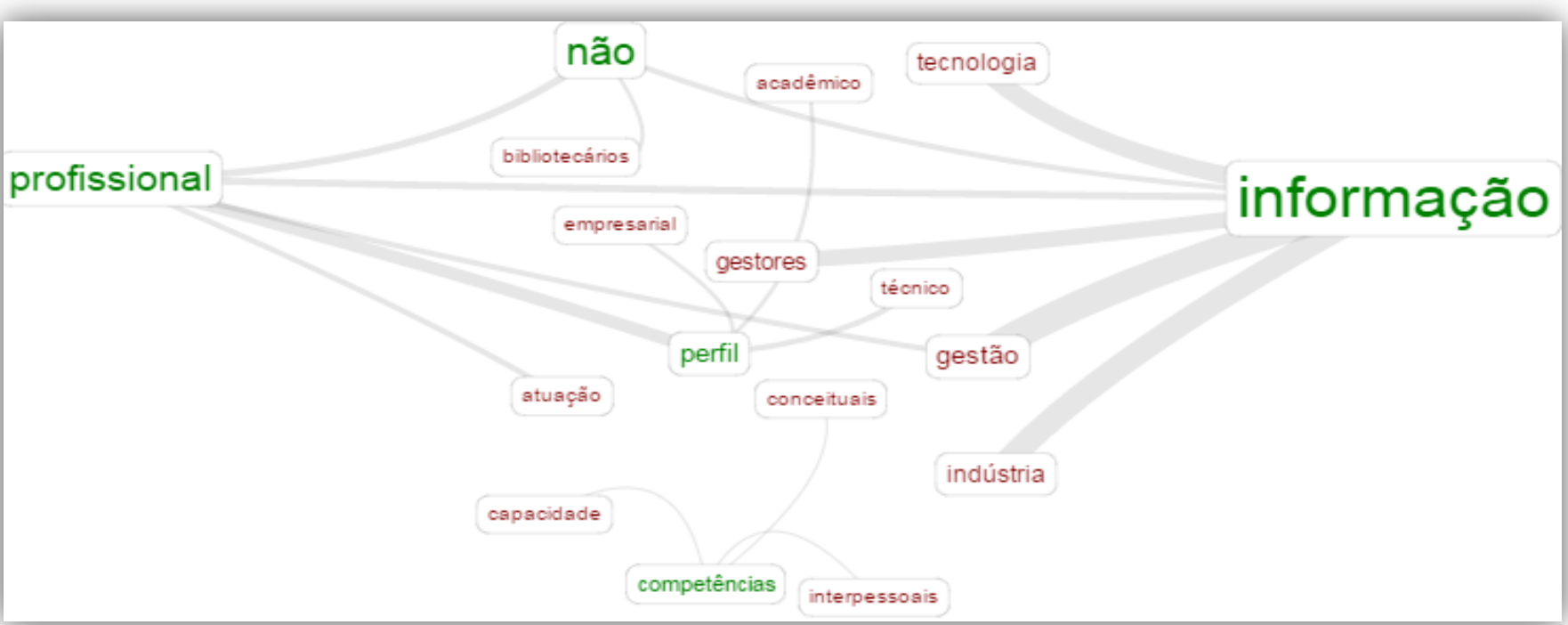

Fuente: Silva, E. Valadares y otros. O perfil dos gestores de informação para a indústria capixaba. Ciência da Informação, 37(1). DOI: https://dx.doi.org/10.1590/S0100-19652008000100007 


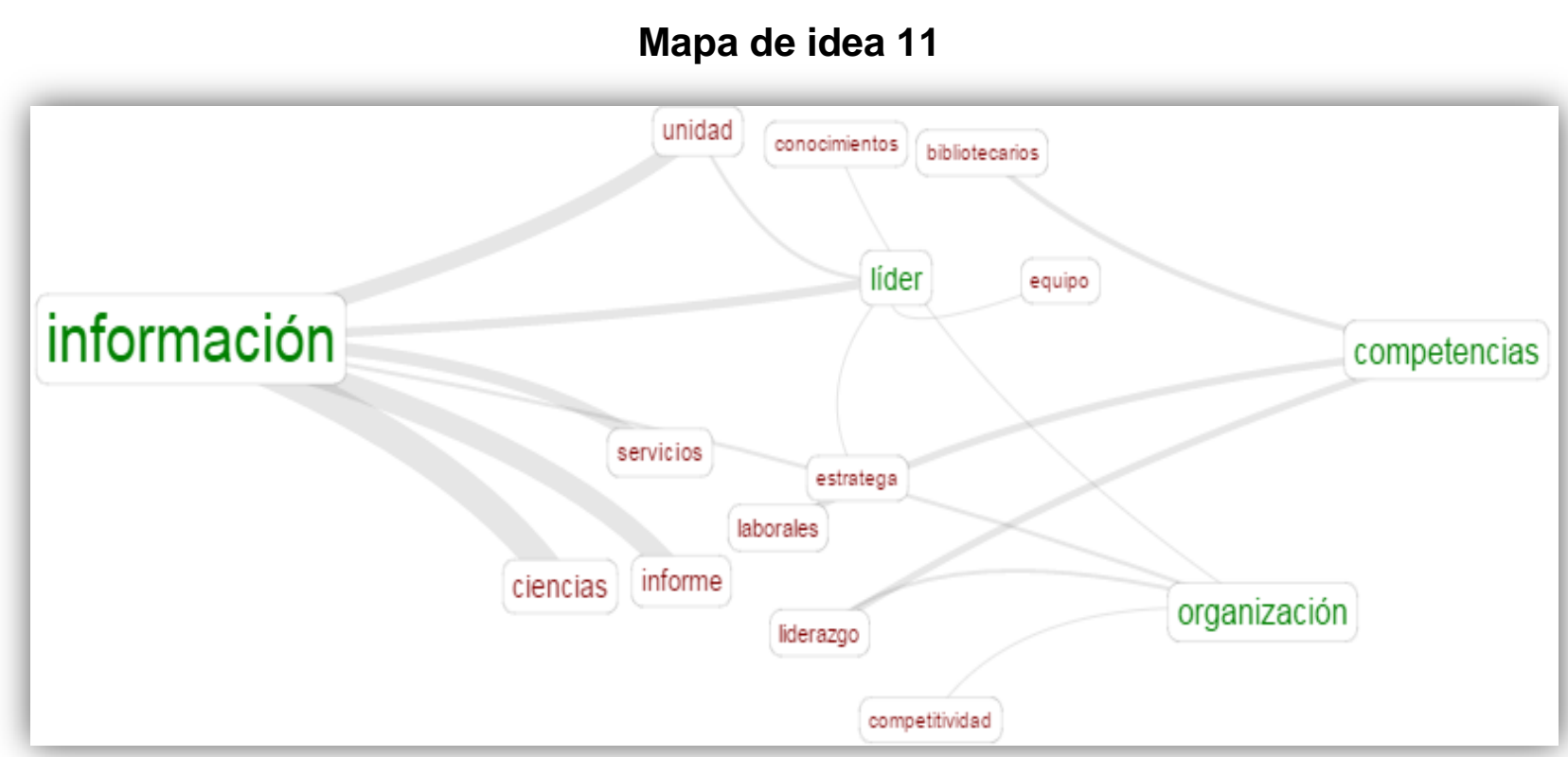

Fuente: Flores de la Fuente, M. (2013). Competitividad y liderazgo: elementos vitales para gerentes de unidades de información. e-Ciencias de la Información, 3(1). DOI: http://dx.doi.org/10.15517/eci.v3i1.8498

\section{Mapa de idea 12}

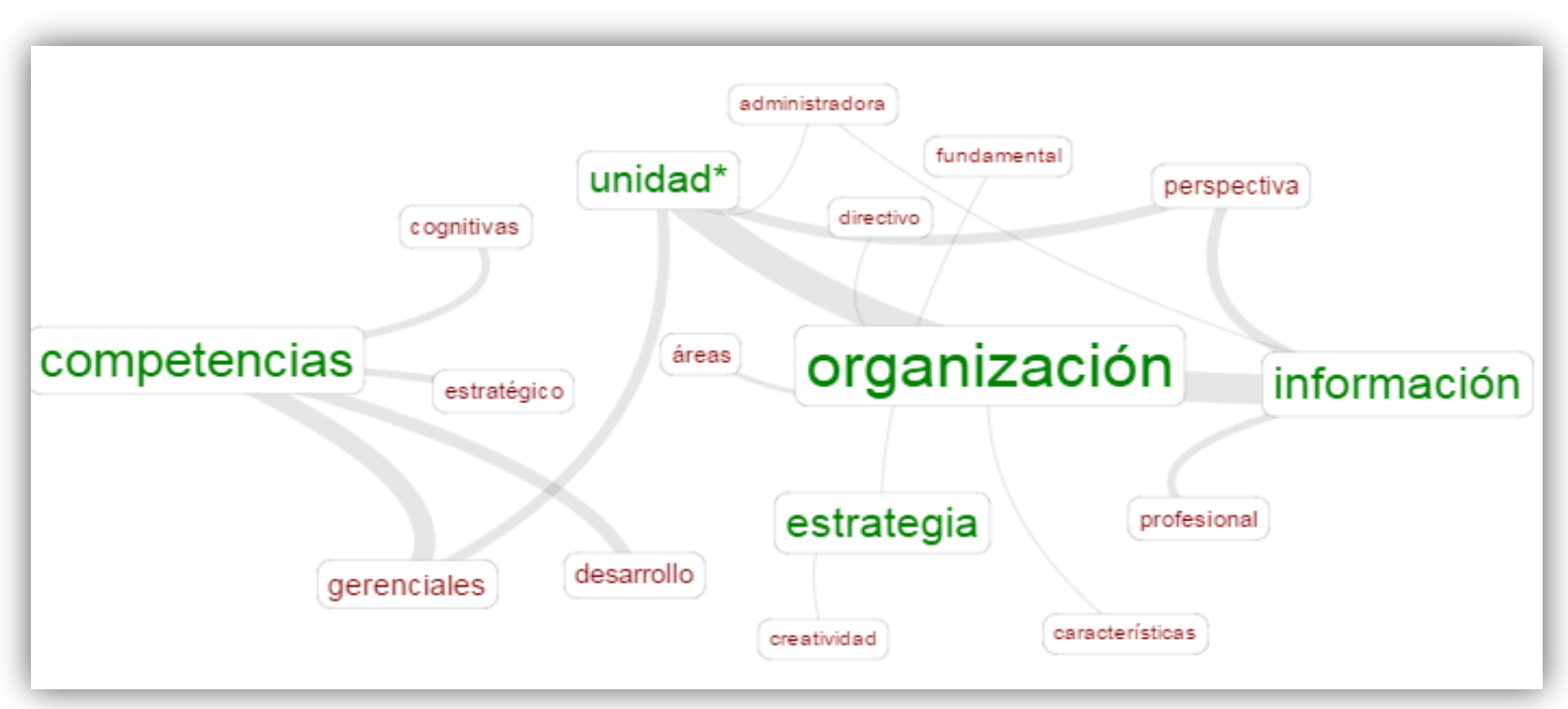

Fuente: Téllez, L. (2005). Pensamiento estratégico y desarrollo de competencias gerenciales: una perspectiva desde las unidades de información. En Códices. 1 (2). 
En esta área se encontraron pocos trabajos, los autores que más sobresalen son Téllez Tolosa, Da Silva y Flores de la Fuente, quienes explicitan las competencias de los profesionales de la información en la práctica administrativa a partir de los procesos de gestión de la información y el liderazgo.

\section{d) ÁREA DE LAS TIC}

\section{Mapa de idea 13}

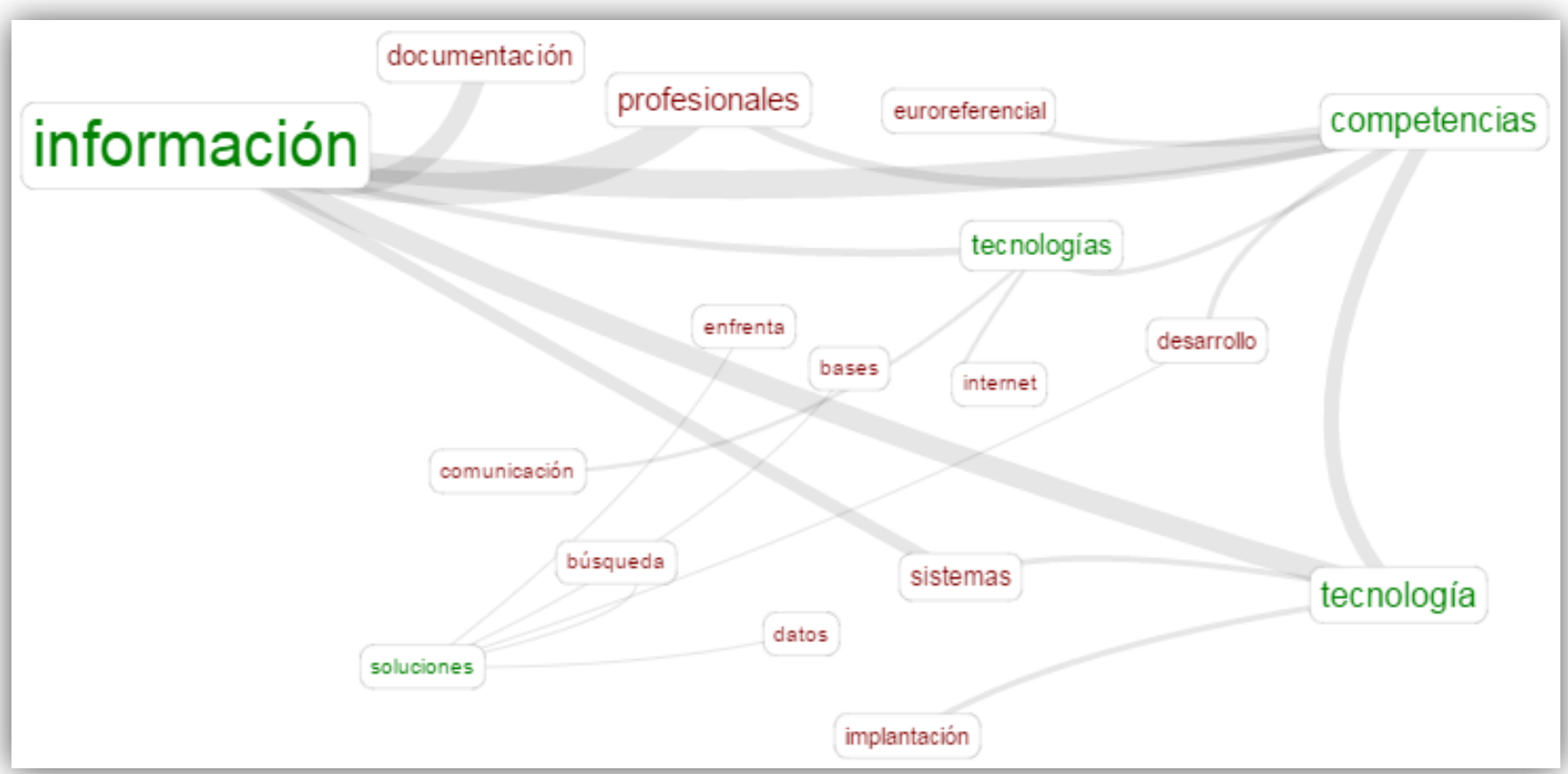

Fuente: Fuentes de Iturbe, P. (2006). Competencias y uso de tecnologías en sistemas de información. En Boletín Informativo del Observatorio para la CiberSociedad. Vol.38. 


\section{Mapa de idea 14}

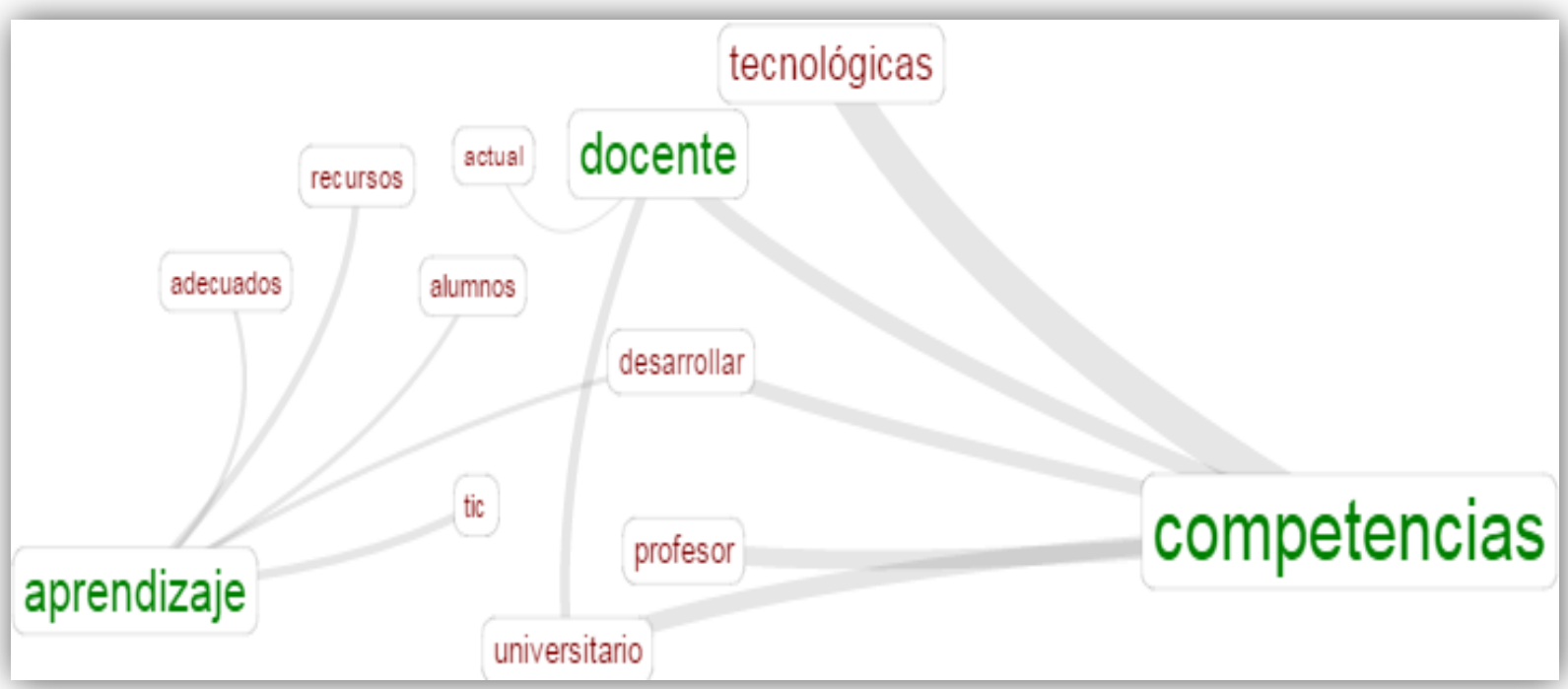

Fuente: Tejada Artigas, Carlos Miguel. 2011. Competencias tecnológicas de los profesores universitarios en información y documentación. Disponible en http://hdl.handle.net/10366/119624

\section{Mapa de idea 15}

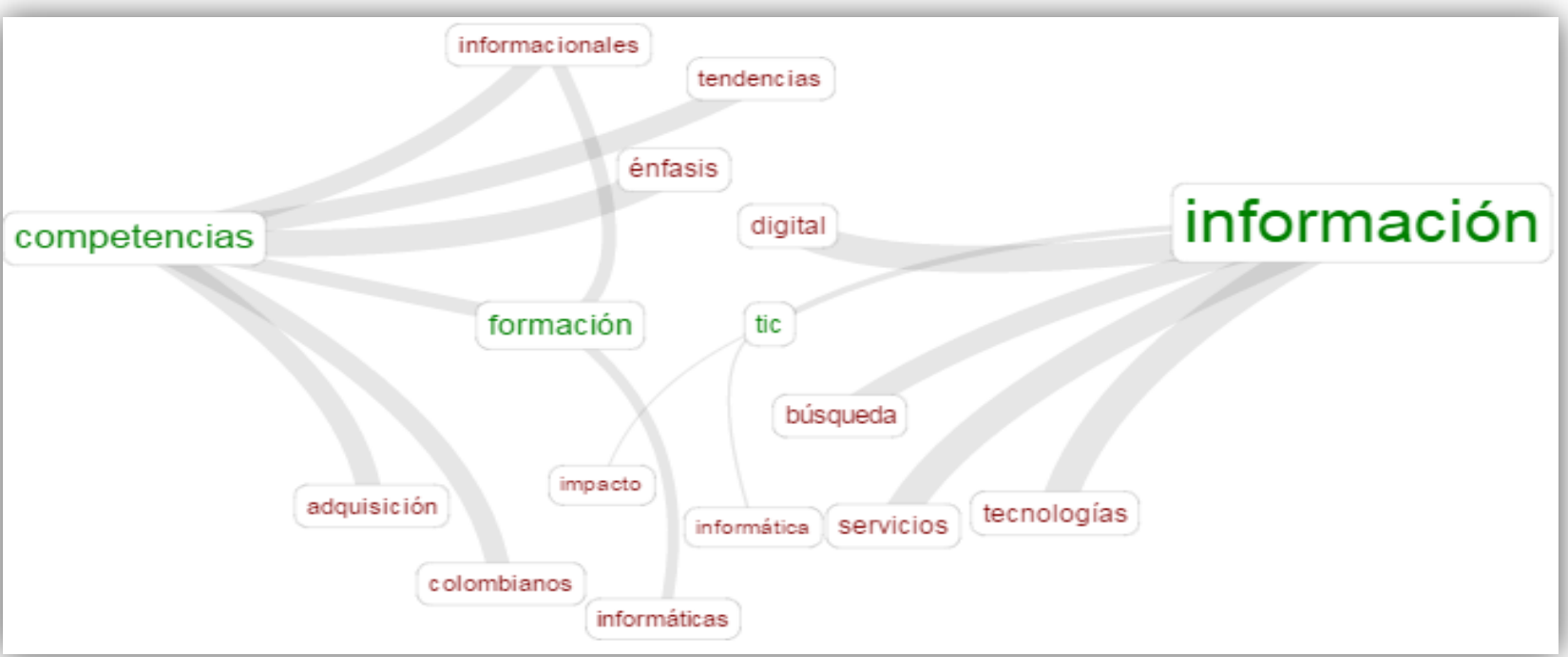

Fuente: Uribe, A. y Castaño, W. (2010). La formación en competencias informáticas e informacionales desde la Escuela Interamericana de Bibliotecología con el apoyo de una plataforma de E-Learning. Experiencias y resultados. Hélice: Revista Venezolana de Ciencias de la Información, 2 (2). Disponible en http://hdl.handle.net/10760/17875 


\section{Mapa de idea 16}

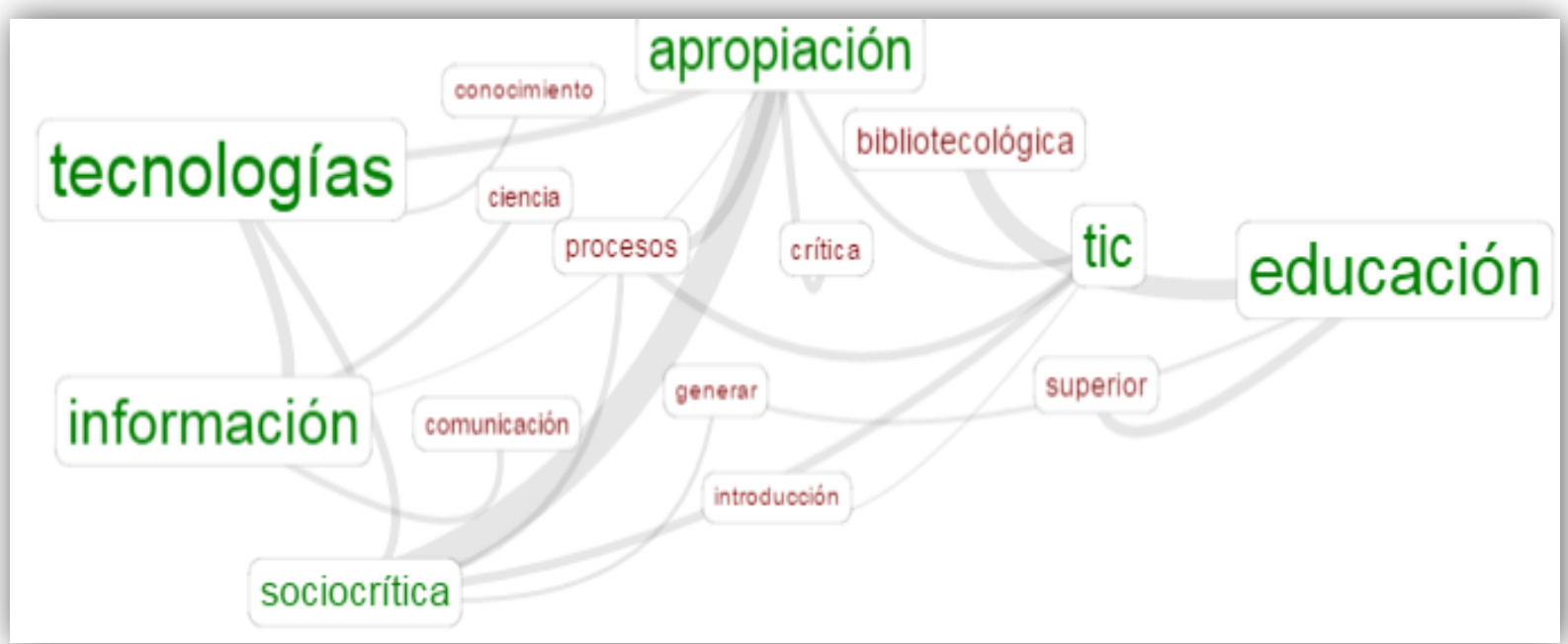

Fuente: Pirela, J. (2013). La formación bibliotecológica para la apropiación socio crítica de las Tecnologías de la Información y la Comunicación. México: IIBI-UNAM.

Los estudios hacen énfasis en las necesidades de formación y educación virtual, cuyas competencias del profesor de las TIC se orientan al conocimiento y uso de plataformas educativas, contenidos digitales y aplicaciones para la evaluación y representación del conocimiento.

\section{Resultados de la encuesta sobre las características del perfil del profesor}

La base de datos del Sistema Nacional de Información en Educación Superior de ColombiaSNIES- registra seis universidades que ofrecen formación en bibliotecología- archivística. La investigación obtuvo información de los programas de cuatro universidades, dos de carácter público (Antioquia y Quindío) y dos privadas (La Salle y Javeriana); de la Fundación Universitaria UNINPAHU y de la Corporación Universitaria de la Costa-CUC no se encontró información. Estos Programas registran 169 profesores con vinculación a término indefinido, 32 de planta o en propiedad, 10 ocasional o a término definido y 121 profesores de carácter interino o de cátedra (por hora trabajada). De este universo de profesores, 91 diligenciaron la 
encuesta y cuatro fueron diligenciados por parte del equipo de investigación, con la información extraída de la base datos CVLAC, EXIT y el sitio web de las Universidades. Las gráficas muestran la participación por universidad y el tipo de contratación de los profesores. La llustración 1 muestra el porcentaje de participación por universidad.

\section{llustración 1}

\section{Participación por universidad y tipo de contratación}

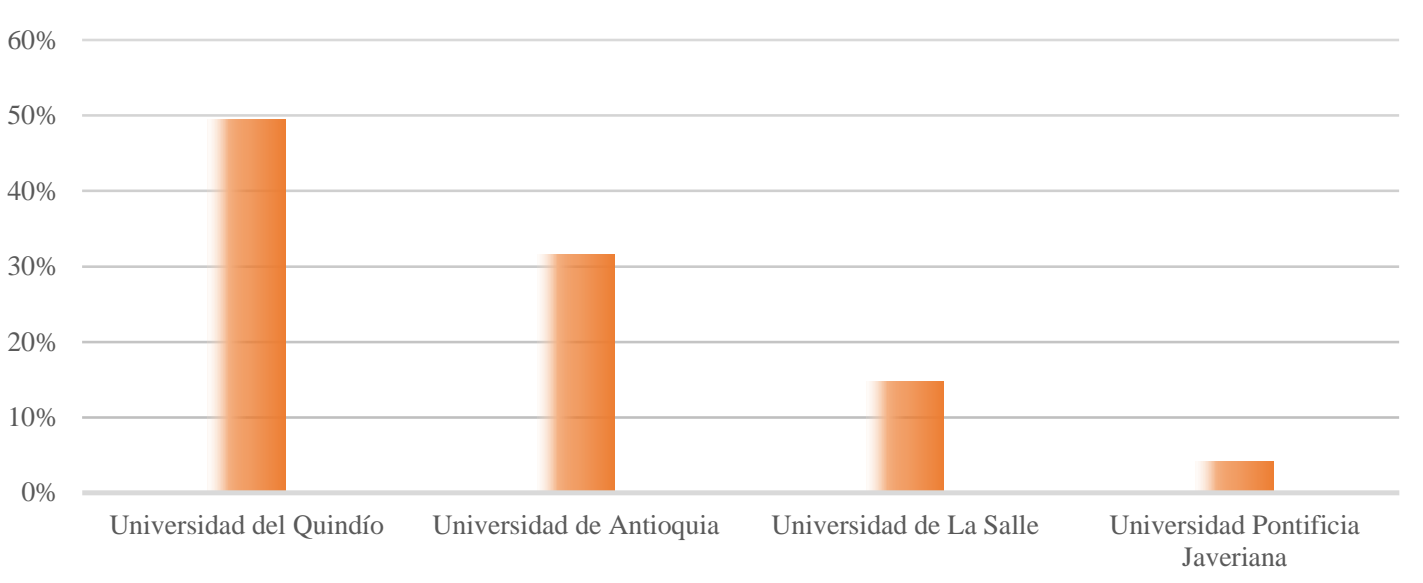

Fuente: Elaboración propia. Diseño de la investigación.

Es de resaltar que el mayor número de profesores pertenece a la Universidad del Quindío, que oferta el programa en la modalidad; el tipo de vinculación del profesor con la universidad es de carácter interino o por hora cátedra con el $71 \%$. En cuanto a los datos generales se encontró que el $58 \%$ corresponde al género masculino y con predominio el rango de edad entre $36-40$, del $24 \%$.

Las principales características del profesor del área, en Colombia, se agrupan en los tres ejes misionales de la educación superior: docencia, investigación y extensión-proyección a la sociedad; características que se plasman en el Cuadro 2. 


\section{Cuadro 2}

\section{Características del profesor}

\begin{tabular}{|c|c|c|}
\hline Ejes misionales & Características & Porcentaje \\
\hline \multirow{4}{*}{ Docencia } & Experiencia docente & $67 \%$ \\
\cline { 2 - 3 } & Capacitación docente & $58 \%$ \\
\cline { 2 - 3 } & Formación de grado (área) & $47 \%$ \\
\cline { 2 - 3 } & Formación de grado (otras áreas) & $51 \%$ \\
\cline { 2 - 3 } Investigación & Formación pedagógica & $63 \%$ \\
\cline { 2 - 3 } & Áreas de investigación: fundamentación y & $56 \%$ \\
\hline \multirow{2}{*}{$\begin{array}{c}\text { Extensión } \\
\text { proyección a la } \\
\text { sociedad }\end{array}$} & caracterización de la información & $33 \%$ y 18\% \\
\hline
\end{tabular}

Fuente: Elaboración propia. Diseño de la investigación.

Una condición reiterativa del ejercicio docente en educación superior es la no exigencia de conocimientos y experiencia pedagógica en la contratación de un profesional para ser profesor; situación que es común en los profesores adscritos a la formación profesional de los profesionales de la información, al encontrar que el $48 \%$ no participan en actividades de actualización pedagógica. No obstante, algunos de los profesores encuestados manifiestan tener formación pedagógica adquirida, en la mayoría de los casos, con la realización de diplomados o estudios de postgrados. La actividad de mayor aparición en el aspecto de formación pedagógica es el diplomado, seguido de la maestría en docencia universitaria. El número más alto de profesores con este tipo de formación corresponde a los adscritos a la Universidad del Quindío. La gráfica muestra los temas de capacitación docente y modalidad. 


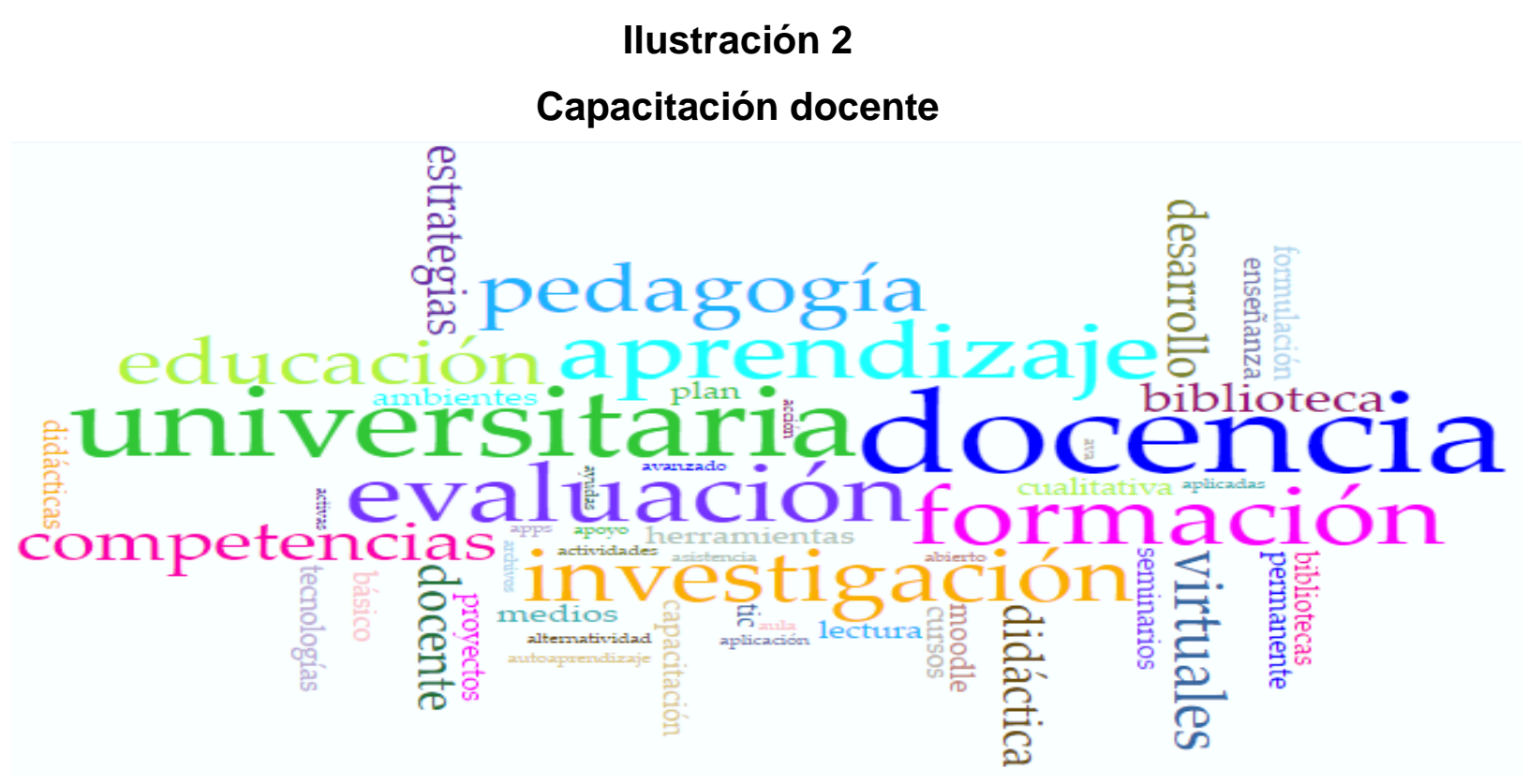

Fuente: Elaboración propia. Diseño de la investigación.

\section{Conclusiones}

El conocimiento del perfil docente exige la mirada de dos aspectos, uno relacionado la comprensión de los factores propios a la IES, pues la naturaleza de la institución (pública o privada) determina los criterios de contratación y los salarios, ambos aspectos precisan la calidad y con ella el perfil del docente; el otro aspecto se relaciona con la propuesta formativa y el plan de estudio y su vínculo con las tendencias, innovaciones y demandas en el área bibliotecológica, archivística y de ciencia de la información; el conocimiento de estas posibilitan mejores perfiles y con ellos mejores niveles de formación.

El perfil del profesor parte del convencimiento, de un lado, del papel clave que le corresponde desempeñar en los tiempos actuales y, de otro, de la importancia estratégica, para el futuro de la profesión, de la IES institución a la cual sirve y del país. En consecuencia, el perfil del profesor universitario, de bibliotecología, archivística y ciencia de la información, abarca un conjunto de componentes complejos y multidimensionales, entre los que se encuentran su formación académica inicial (grado), sus estudios de posgrado, de actualización y 
capacitación; la experiencia matizada por los cargos desempeñados, las funciones desarrolladas y las propuestas de innovación institucional; componentes que determinan cuáles son aquellos rasgos característicos del perfil del profesor en el área y, por ende, identifica qué competencias docentes debe tener.

Entre los factores determinantes en el perfeccionamiento del perfil del profesor universitario, se destacan los procesos de autoevaluación, con fines de acreditación de alta calidad, el concurso público de méritos docentes y el régimen salarial y prestacional de las IES de carácter público; esto conlleva a la cualificación de los profesores, tanto en formación posgraduada (maestrías y doctorados) como con la investigación y la productividad académica, reflejada en publicaciones de artículos en revistas indexadas, así como en proyectos de investigación interdisciplinar e interinstitucional y en la generación de cursos de extensión y consultorías.

Específicamente en lo referido al perfil del profesor en el área en Colombia, hay que decir que aunque la formación profesional en bibliotecología, archivística y ciencia de información es impartida por IES, de amplio reconocimiento a nivel nacional, la extensa búsqueda documental no arrojó resultados satisfactorios en el tema relacionado con el perfil docente al no encontrar estudios realizados en el país y un reducido número en el ámbito Iberoamericano. En especial se resalta que bajo los términos perfil-archivística-Colombia, perfil-bibliotecología-Colombia y perfil-documentación-Colombia no se obtuvo ningún resultado relacionado con el perfil docente.

Los estudios encontrados se vinculan con temas afines como currículo, planes de estudio, perfiles, competencias; es decir, la otra cara de la moneda: la formación profesional. Esta ausencia de investigaciones puede interpretarse, de un lado, desde las dinámicas de la educación superior y la vinculación de profesores, donde se tiene en cuenta los criterios de formación graduada, posgraduada, experiencia laboral e investigativa y producción académica y en ningún momento se tiene en cuenta 0 , por lo menos, no explícitamente, la formación pedagógica; y de otro, desde los intereses del desarrollo bibliotecológico, cuya preocupación 
por el perfil docente no ha estado presente en las agendas de investigación en bibliotecología, como parte del entorno que condiciona las tendencias de la producción y comunicación científica que caracterizan el desarrollo del conocimiento en el área; en este sentido, se requiere de una mayor comprensión en cuanto al perfil y competencias que debe reunir el docente de bibliotecología para responder tanto a las necesidades reales del sector relacionado con la transferencia de la información, como a contribuir con la calidad y pertinencia de los programas de la IES, pues el docente genera valor al programa académico y a la institución y ello, implícitamente, eleva la calidad de la universidad.

En la caracterización del profesor, en el área, desde los resultados de la encuesta y el estudio de las currículas docentes, no es posible asumir una sola postura para determinar el perfil del docente de bibliotecología, debido tanto al carácter interdisciplinar de la profesión, como a los criterios que hacen parte de un ideal de búsqueda de la calidad en la IES y de las misiones del profesor.

Finalmente, en Colombia, las condiciones de selección, contratación y perfeccionamiento del profesor universitario son favorables, debido a las situaciones del marco jurídico de la Ley 30 , que da autonomía a las instituciones para diseñar dichos procesos; y por el Decreto 2912 del 2001: Régimen de Salarios y Prestaciones se establecen parámetros para el mejoramiento docente, como lo es la evaluación periódica de méritos y la constitución del salario con base en un sistema de puntos; sistema que fija el salario de acuerdo con la experiencia profesional, el nivel de formación y la producción académica, haciendo del salario un factor diferenciador del profesor de las IES públicas con los demás funcionarios del Estado; además de la legislación, los procesos de autoevaluación con miras a la acreditación de los programas de educación superior juegan un papel determinante en la calidad de los docentes, pues el Consejo Nacional de Acreditación determina el tipo de docente que debe tener un programa, al describir las características requeridas, en cuanto cantidad, pertinencia, calidad y dedicación, de acuerdo con la naturaleza de la institución y del programa que aspira a obtener la acreditación de alta calidad. 


\section{Referencias}

Alfaro, H. (2010). Estudios epistemológicos de Bibliotecología. México: UNAM.

Bozu, Z. \& Canto, P. (2009). El profesorado universitario en la sociedad del conocimiento: competencias profesionales docentes. Revista de Formación e Innovación Educativa Universitaria, 2(2), 87-97.

Castro, Y., y Chávez, Y. (2012). La interdisciplinariedad en la formación profesional del analista de información: propuesta de competencias. Ciencias de la Información, 43 (2).

Durrieu, M. y otros (2011). Competencias profesionales: una mirada desde la formación en los procesos técnicos. VII Encuentro Internacional y III Nacional de Catalogadores, Argentina.

Fuentes de Iturbe, P. (2006). Competencias y uso de tecnologías en sistemas de información. En Boletín Informativo del Observatorio para la CiberSociedad. Vol.38.

Linares, R. (2015). La Bibliotecología en dos tiempos. Revista Cubana de Información en $\begin{array}{lllll}\text { Ciencias de la } & \text { Salud, } 26 & \text { (4). Recuperado de }\end{array}$ http://scielo.sld.cu/scielo.php?script=sci arttext\&pid=S2307-

\section{$21132015000400004 \& \operatorname{lng}=\mathrm{es} \& \ln \mathrm{n}=\mathrm{es}$}

Ministerio de Educación, Colombia. Ley 30 de 1992. Disponible en http://www.mineducacion.gov.co/1621/articles-

Ministerio de Educación, Colombia. Decreto 2912 del 31 de diciembre de 2001. Disponible en http://www.mineducacion.gov.co/1621/articles-86123 archivo pdf.pdf

Ministerio de Educación, Colombia. ¿Qué es la educación superior?. Disponible en: http://www.mineducacion.gov.co/1621/article-196477.html

Jaramillo, O. (2017). El perfil del profesor de bibliotecológica-archivística en Colombia y su vinculación con el modelo educativo: informe de investigación. Medellín: Escuela Interamericana de Bibliotecología, Universidad de Antioquia.

Pirela, J. (2013). La formación bibliotecológica para la apropiación socio crítica de las Tecnologías de la Información y la Comunicación. México: IIBI-UNAM.

Rendón, M. (2008). Ciencia bibliotecológica y de la información en el contexto de las ciencias sociales y humanas. Epistemología, metodología e interdisciplina. Investigación 
bibliotecológica, 22(44).

Recuperado

de

http://www.scielo.org.mx/scielo.php?script=sci arttext\&pid=S0187-

358X2008000100004\&lng=es\&tlng=es.

Ríos Ortega, Jaime. (2007). La teoría en la educación bibliotecológica: directrices básicas para su enseñanza. Investigación bibliotecológica, 21 (42). Recuperado de http://www.scielo.org.mx/scielo.php?script=sci arttext\&pid=S0187-

$\underline{358 \times 2007000100006 \& \operatorname{lng}=e s \& t \operatorname{lng}=e s .}$

Ríos, A., y Sánchez, M. (2011). El perfil actual del personal catalogador: adecuación entre la formación universitaria y la demanda laboral. Anales de Documentación, 14 (2), 1-17.

Rodríguez, A. (2012). Claves para la implementación de los lineamientos recursos, descripción y acceso. Investigación Bibliotecológica: Archivonomía, $\begin{array}{llll}\text { Bibliotecología Información, } 26 \quad \text { (56). DOI: } & \text { e }\end{array}$ http://dx.doi.org/10.22201/iibi.0187358xp.2012.56.33177.

Rodríguez, S. (2008). Las competencias profesionales en las ciencias de la información. En ACIMED, 20(1).

Setién-Quesada, Emilio. (2007). Consideraciones sobre la bibliología desde la perspectiva de la teoría bibliológico-informativa. ACIMED, 15 (2). Recuperado de http://scielo.sld.cu/scielo.php?script=sci arttext\&pid=S102494352007000200007\&lng=es\&tlng=es.

Silva, E. Valadares y otros. O perfil dos gestores de informação para a indústria capixaba. Ciência da Informação, 37(1). DOI: https://dx.doi.org/10.1590/S010019652008000100007

Special Libraries Association. (2016). Competencies for Information Professionals. Disponible en: https://www.sla.org/about-sla/competencies/\#sthash.ZfScXdkM.dpuf

Tejada Artigas, Carlos Miguel. 2011. Competencias tecnológicas de los profesores universitarios en información y documentación. Disponible en http://hdl.handle.net/10366/119624

Téllez, L. (2005). Pensamiento estratégico y desarrollo de competencias gerenciales: una perspectiva desde las unidades de información. En Códices. 1 (2). 
Uribe, A. y Castaño, W. (2010). La formación en competencias informáticas e informacionales desde la Escuela Interamericana de Bibliotecología con el apoyo de una plataforma de E-Learning. Experiencias y resultados. Hélice: Revista Venezolana de Ciencias de la Información, 2 (2). Disponible en http://hdl.handle.net/10760/17875

\section{Notas de la Autora}

1 Texto derivado de la investigación: Perfil del docente y su vinculación con el modelo educativo en la educación bibliotecológica y de documentación en Iberoamérica y El Caribe. Coordinado por el Instituto de Investigaciones Bibliotecológicas y de la Información de la Universidad Nacional Autónoma de México.

${ }^{2}$ Orlanda Jaramillo. Profesora-investigadora. Escuela Interamericana de Bibliotecología de la Universidad de Antioquia, Apartado Aéreo 1226, Medellín, Colombia. Bibliotecóloga, Doctora en Educación de la Universidad de Antioquia. orlanda.jaramillo@udea.edu.co

3 En Colombia todas instituciones que ofrecen formación profesional en Bibliotecología, Archivística, Documentación y Ciencia de la Información incluyen en el título la denominación de Bibliotecología; por ello, el término profesor en bibliotecología-archivística abarca las demás denominaciones. 